\title{
ESTABLISHING AN ARCHIVE OF PAPERS IN COMPUTATIONAL ELECTROMAGNETICS
}

\author{
C.W. Trowbridge ${ }^{*}$, J.K. Sykulski ${ }^{\dagger}$ \\ *D'Arcy's Field's, Frilford, Oxford, OX13 5NS, UK, bill@trowbridge.org.uk \\ ${ }^{\dagger}$ School of ECS, University of Southampton, SO17 1BJ, UK, jks@soton.ac.uk
}

Keywords: archive, references, attribution, reviewing.

\begin{abstract}
This paper builds on the ideas first put forward at the COMPUMAG conference, Aachen, 2007, and argues that a definite archive of publications in the area of Computational Electromagnetics would benefit the community. Such an archive would aid researchers in placing their work in proper context and would facilitate reviewing process for conferences and journals.
\end{abstract}

\section{Introduction}

We will address some of the issues raised in previous papers on this topic at Compumag Shenyang [1] which discussed some of the key developments in the subject and their attribution, and at Compumag Aachen [2] which discussed the criteria for a definitive archive. Since then the authors have discussed this with other colleagues and a view has emerged that there is a need for a definitive archive of important work to be made available to the community. We believe that time for action is now and as we are addressing a different subset of our community and importantly one with classical roots with a premier learned institution we will repeat the main points again. We have argued that the Compumag and CEFC conferences alone have provided the community with a very large record published annually, that in total amounts to several thousand of papers.

There are several areas of concern:

- The record of early work is in danger of being lost, e.g. the Compumag Oxford (1976) [2] and Grenoble (1979) [3] which were published by the organising bodies with limited number of copies. The same also applies to CEFC which grew out of a series of user meetings held in the USA [4]. There were many papers of importance that should be made available to the modern community.

- The mapping of innovative work onto the main areas of scientific development so that a better understanding of attribution and citation can be made. A compelling reason to do this is to limit the amount of duplication that is appearing in the literature and to assist the refereeing process.

- In addition to the published papers a definitive bibliography of published books that remain in print, or are available on the web, or are to be found in most scientific libraries should be established.

- The body of knowledge that is catalogued is in itself of historical significance but perhaps of greater importance is the identification of problem areas for the future.

\section{Endangered papers}

To assist in justifying this concern it may be helpful to examine the first Compumag proceedings in a little more detail. Recently a facsimile copy has been made of all the papers and a PDF file of the entire proceedings produced which is planned to be posted on the Compumag Society Web site [5]. The conference was timely as the use of digital computers was becoming widespread and the dawn of the workstation and personal machines just beginning to blossom. In order to ensure a truly representative coverage the organizers decided to invite a number of established researchers to give the oral presentations and many new developments were reported. A key element of these oral papers was to allow adequate time for discussion. This discussion was published with the proceedings and indeed can be seen now, in retrospect, as a significant contribution. For all sorts of reasons this practice was not continued in later meetings with the emphasis changing to poster presentations and panel discussions. Another factor was the high proportion of delegates from National Laboratories and Industry present and enriching the discussion. This was also true for many meetings held at that time but is now not as common as industry no longer develops methods to the same extent.

\section{Criteria for inclusion of innovative work}

In order to establish a coherent mapping we need to define a criterion for inclusion. No single paper, of course, is completely new but it must not merely duplicate earlier work and must contain at least one innovative step. A significant step forward is valid however if it improves the efficiency and applicability of an existing method or indeed adapts a technique previously applied to a different discipline say from a branch of mathematics. An example from history is that of Richardson (1910) [6], who rigorously established the five point finite difference formula and applied it to real engineering problems. Whilst Richardson was drawing partially on the work of Runge (1908) and Boltzmann (1892) he qualifies as a significant innovator as he established the rules of the method and perhaps ushered in the modern age of Numerical Methods. On the other hand, if a researcher publishes a paper which 
uses a method that he, or someone else for that matter, had previously innovated and then merely applies it to another problem without any aspects of novelty, interesting as this may be in itself (or from application point of view) and thus worthy of publication, it should not qualify as innovative in the context of Computational Electromagnetics (CEM).

One scenario could be:

- Define subject areas, e.g. Fundamentals and Theory, Differential Methods, Integral Methods, Hybrid and Semi-analytical, Numerical Techniques, Software Methodology, Material Modelling, Mesh Generation and Adaption, Post-Processing, Coupled Problems, Optimisation and CAD.

- Compile a list of candidate papers utilizing input from the community.

- Appoint a working party to make the selection; this already has started within the remit of the International Compumag Society but we suggest representatives from other organisations should also be involved.

- Establish a file of review papers perhaps drawing on the existing review articles that have been published in the ICS Newsletter [5] and commissioning new ones to cover gaps, see section 5 .

\section{Book bibliography}

A list of published books and monographs with reviews attached should also be added to the archive and include not only those that are regularly cited by researchers but also those which relate CEM to broader areas. As argued before [1], CEM is both a special case and part of the wider subject of computational mechanics, with its own very rich literature and significant achievements. Similarly, field simulation aided design draws on advances in general optimisation techniques, coupled formulations on developments in other branches of physics, and so on - care must be taken when establishing a list of relevant books but the potential value of such a catalogue should not be underestimated.

\section{The role of the ICS Newsletter}

It has been the tradition of the ICS Newsletter [5], since the first issue which appeared on 26 October 1993 , to publish technical articles on various 'hot topics' of CEM. Initially these articles were shorter and reported on recent advances in a particular area - they were in fact more like learned society journal papers, although invited rather than submitted - but gradually they evolved into more substantial reviews, often of ten pages or more. The importance of these reviews was recognised so that a special co-editor of ICS Newsletter was appointed to solicit articles and oversee this series of publications to make sure that important issues were raised and discussed. It was the feature especially of the early publications that often a lively discussion followed presenting different points of view. The articles are now probably the most important service to the community by the Society, in addition of course to organising the biennial COMPUMAG conference. A common feature of the most recent publications in the Newsletter is that they describe the state of the art, emphasise the important milestones, describe the most recent advances and provide a rich list of references; it could therefore be argued that they are indeed true reviews. It may therefore be the most efficient way forward to use these articles as the starting point when implementing the ideas of Section 3, as a lot of ground work has already been covered. However, the list of topics which would benefit from having a definite archive is much broader than those already covered in the Newsletter, so more work needs to be done.

\section{Future plans}

The full paper will elaborate on the above issues with further suggestions and recommendations. A case study will be incorporated to demonstrate how the creation of the archive could be achieved following a preferred scenario - this should not be viewed as a definite proposal but more as an example using a selected narrow research topic. Feedback from researchers will be an essential factor in establishing an archive system to which the community would subscribe. The CEM Community should accept this as a challenge to create appropriate mechanisms, establish a process and provide reliable feedback mechanism.

\section{Conclusions}

The need for creation of an archive of publications in Computational Electromagnetics has been emphasised. The main goal is to assist researchers, especially the young ones, in establishing quickly the 'state of the art', provide a definite point of reference and facilitate reviewing processes for conferences and journal publications in the CEM field. The International Compumag Society should take a leading role.

\section{References}

[1] C. W. Trowbridge and J. K. Sykulski, "Towards Establishing a Definitive Archive of CEM Papers", Proceedings of COMPUMAG Aachen, Volume I, OA1-1, pp. 7-8, (2007).

[2] C. W. Trowbridge and J. K. Sykulski, "Some Key Developments in CEM and their Attribution", IEEE Trans. Magn., 42, (4), pp. 903-906, (2006).

[3] J. Simkin and C. W. Trowbridge (Eds), Proc. COMPUMAG Oxford, Rutherford Lab, (1976).

[4] ICS Web Site, http://www.compumag.co.uk/

[5] International Compumag Society Newsletter, ISSN 1026-0854

[6] L. F. Richardson, "The approximate arithmetical solution by finite differences of physical problems ...", Phil. Trans. Royal Society, 210A, pp. 307-357, (1910). 